\title{
Complex study of modified binder properties
}

\author{
Viktoria Viktorovna Nelubova \\ Department of material science and material technology \\ Belgorod State Technological University named after V.G. \\ Shoukhov \\ BSTU named after V.G. Shoukhov \\ Belgorod, Russia \\ 308012, Kostukova St., 46 \\ vvnelubova@gmail.com \\ Pengkun Hou \\ University of Jinan (UJN) \\ Jinan City, Shandong Province China \\ №.336, Nanxinzhuang, West Rd. \\ pkhou@163.com

\section{Valeria Valerievna Strokova} \\ Department of material science and material technology \\ Belgorod State Technological University named after V.G. \\ Shoukhov \\ BSTU named after V.G. Shoukhov \\ 308012, Kostukova St., 46 \\ Belgorod, Russia \\ vvstrokova@gmail.com
}

\author{
Lok Pratar Singh \\ CSIR-Central Building Research Institute \\ Uttarakhand, India \\ 247667, Roorkee, \\ lpsingh.cbri@gmail.com
}

Daria Dmitrievna Netsvet

Department of material science and material technology

Belgorod State Technological University named after V.G. Shoukhov

BSTU named after V.G. Shoukhov

Belgorod, Russia

308012, Kostukova St., 46

netsvet_dd@mail.ru

Diana Olegovna Bondarenko

Department of material science and material technology

Belgorod State Technological University named after V.G. Shoukhov

BSTU named after V.G. Shoukhov

Belgorod, Russia

308012, Kostukova St., 46

di_bondarenko@mail.ru

collected data, the optimal composition with high durability indexes was chosen.

Keywords - composite binder, mechanical activation, nanostructured modifier, silicate composition.

\section{INTRODUCTION}

One of the most important challenges of the modern building industry is the search for simple technological and economical approaches aimed at increasing the efficacy of the binders and materials on their base, each component of which plays its own role in hardening and structureformation processes. One way to solve these tasks is to use composite binders based on the components of different origins instead of the traditional cement [1-6], to use a variety of modifiers, including nanodispersed ones [7-8]. The high efficacy of nanotechnological solutions for building industry has been proved by the numerous studies [10-15]. It is largely due to the quality product increase caused by the improvement of the basic technological and operational characteristics, likewise, by creating the unique properties of end-products.

The authors developed the nanostructured binder (NB) based on the raw materials of different composition base and origins [16-17]. The proposed material can be used in a variety of spectrum of building purposed composites not 
only as the basic binder component, but also as an active modifying additive - a nanostructured modifier (NM). In the previously conducted research, the opportunity to use NB as the high-active modifying component in the production of autoclave building materials for various functional purposes has been proved [18-19]. The current research focuses on the cement binders and the materials of non-autoclave hardening.

The studies analyze the compositions gained by mixing Portland cement and NB in different proportions that allows assuming about modified binder compositions, which implies "the binder-modifier system". According to the basic component, their order in the system can be changed.

The aim of this research is to study the mechanisms and results of the interaction between the cement and a nanodispersed silica component in modified binder production. The quality increase in cement composites brings about the decrease in expensive, high branded cement consumption; thereby it leads to the cost reduction in building, repairing, and buildings service. Not less important thing will be the improvement in ecological conditions in the zones where the building materials and binders are produced. That happens due to a production reduce and lower emission to the atmosphere.

\section{EXPERIMENTAL PART}

The cement of brand CEM I $42,5 \mathrm{~N}$, produced in CJSC "Belgorod Cement" plant, the characteristics of which as well as the chemical and mineral composition of a cement clinker, are shown in tables 1-3. The characteristics of a nanostructured modifier based on quartz sand of Korochanskoe field and the characteristics of a silica component are depicted in table 4.

TABLE I. CHEMICAL COMPOSITION OF CEMENT CLINKER

\begin{tabular}{|c|c|c|c|c|c|}
\hline \multicolumn{6}{|c|}{ Oxides concentration, m. \% } \\
\hline $\mathrm{SiO}_{2}$ & $\mathrm{Al}_{2} \mathrm{O}_{3}$ & $\mathrm{Fe}_{2} \mathrm{O}_{3}$ & $\mathrm{CaO}$ & $\mathrm{CaO}_{c 8}$ & others \\
\hline 22.26 & 4.96 & 4.48 & 66.73 & 0.29 & 1.28 \\
\hline
\end{tabular}

TABLE II. CANCULATED MINERAL COMPOSITION OF CEMENT CLINKER

\begin{tabular}{|c|c|c|c|c|}
\hline \multicolumn{5}{|c|}{ Clinker mineral composition, \% } \\
\hline$C_{3} S$ & $C_{2} S$ & $C_{3} A$ & $C_{4} A F$ & others \\
\hline 61.7 & 17.2 & 5.5 & 13.6 & 2 \\
\hline
\end{tabular}

TABLE III. CALCULATED MINERAL COMPOSITION FOR PORTLANDCEMENT PROPERTIES CEMI42.5N

\begin{tabular}{|l|c|}
\hline \multicolumn{1}{|c|}{ Index } & Value \\
\hline Normal density, \% & 26 \\
\hline Uniformity in volume changes, mm & 0.12 \\
\hline $\begin{array}{l}\text { Average cement activity aged 28 days, } \\
\text { not less, MPa }\end{array}$ & 40 \\
\hline
\end{tabular}

TABLE IV. CHEMICAL COMPOSITION OF SAND FROM KOROCHANSKOE FIELD

\begin{tabular}{|c|c|c|c|c|c|c|c|}
\hline Oxides & $\mathrm{SiO}_{2}$ & $\mathrm{Al}_{2} \mathrm{O}_{3}$ & $\mathrm{Fe}_{2} \mathrm{O}_{3}$ & $\mathrm{CaO}$ & $\mathrm{MgO}$ & $\mathrm{SO}_{3}$ & others \\
\hline Concentration, \% & 92.65 & 4.18 & 0.6 & 1.69 & 0.69 & 0.19 & 1.23 \\
\hline
\end{tabular}

Production of the nanostructured binder is based on long-term stage-grinding of silica containing raw materials in water medium at higher-level temperature $\left(60-80{ }^{\circ} \mathrm{C}\right)$ within the optimal range of the $\mathrm{pH}$ value. It results in suspension formation with the liquid dispersed environment characterized by the limited concentration of a solid phase (with maximum dilution), equally spread throughout the volume in the form of solid, different-size particles; in this case, this is the quartz sand. The suspension here is characterized by thixotropic flow type that allows it to combine low humidity level (introduced by normal density) with high fluidity. While selecting samples, at the stage of obtaining the binder, the following parameters are monitored: a sieve residue with a cell size of 0,063 , density, humidity and $\mathrm{pH}$. As a result, the authors obtained NB of the silicate composition with the following characteristics (table 5).

TABLE V. PHYSICO-MECHANICAL PROPERTIES OF NANOSTRUCTURED BINDER OF SILICATE COMPOSITION

\begin{tabular}{|l|c|}
\hline \multicolumn{1}{|c|}{ Index } & Value \\
\hline Humidity, $\%$ & 17 \\
\hline Density, $\mathrm{kg} / \mathrm{m}^{3}$ & 2000 \\
\hline Sieve residue $0063, \%$ & less 1 \\
\hline $\mathrm{pH}$ suspension & 9 \\
\hline
\end{tabular}

The nanostructured binder differs by the sufficiently high surface area $-830 \mathrm{~m}^{2} / \mathrm{kg}$, which was determined with the air permeability method with the use of HSD-12, intended for laboratory studies and monitoring of technological processes. All measures and calculations are automated that excludes the subjective error factor. At the same time, NM is characterized with a polydispersed granulometric composition with expressed peaks in the range of $2-3,10-15$ and $60-70 \mu \mathrm{m}$ (figure 1). It is due to the features of its production: wet multi-staged grinding with periodic loading of the initial components in grinding. Such granulometry for a modifier will facilitate its equal spreading between the cement particles as the largest component.

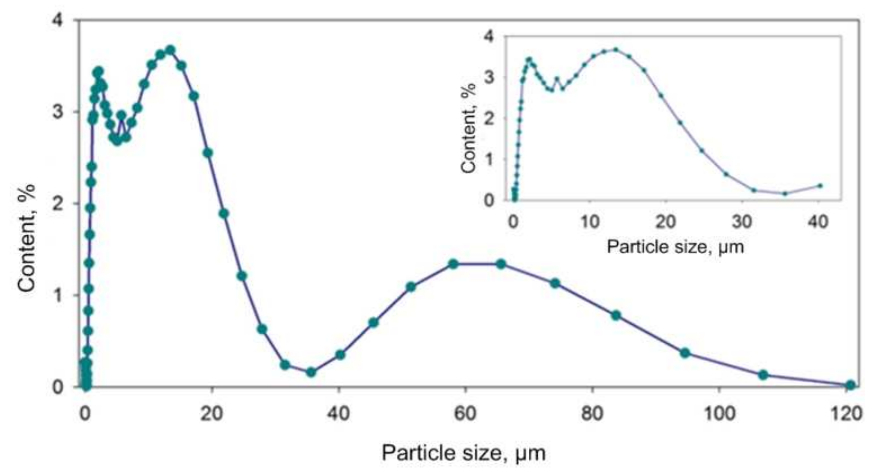

Fig. 1. Granulometry of nanostructured binder

To study the sizes of a highly dispersed binder fraction, the very dilute suspension of NM in distilled water was prepared. Further, the obtained suspension was allowed to subside until the coarse fraction subsided on the bottom of the measuring glass. As a result, a substantially transparent suspension with a finely divided modifier particles 
suspended in the water volume remained, which was subjected to a study on a laser analyzer Microtrac S3500.

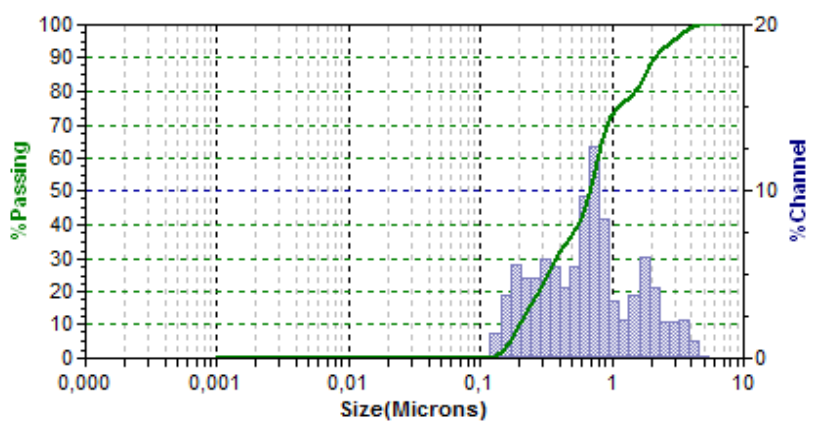

Fig. 2. Granulometric composition of highly-dispersed fraction of nanostructured binder

According to the obtained data (figure 2), the colloidal fraction of the nanostructured binder is primarily introduced with the particles, the size of which is less than $1 \mu \mathrm{m}$. It is worth mentioning that the formation of highly dispersed fraction in the modifier volume in the production process will facilitate its activity increase in the cement system.

NB effective implementation as a modifier was evaluated on the total properties of modified binder with its use: rheological characteristics, hardening kinetics, drying of compositions samples, compressive and bending resistance. The modifier was added into the system instead of one part of the cement, fixed as $10 \%$ in the range of 0 to $100 \%$. The compositions can be divided into two groups: $1-$ 5 - the system "cement - modifier", 6-11 - the system "modifier - cement". This division is reasonable in the view of the fact that in the compositions belonging to the system "cement - modifier" the main component is the material of hydration hardening, which gains its strength due to new hydrate substance formation, causing the paste hardening and adhesion of concrete mixture. In the compositions belonging to the system "modifier - cement", the main component gains its strength due to the moisture remove; the hardening mechanism in this case is polymerizationpolycondesation one.

The rheological characteristics of the nanostructured binder typical to the system "cement - modifier" were studied with the help of Rheotest RN4.1 (rotational viscometer). This device is based on the cylindrical measuring system. The experiment was conducted with the use of a controlled shear stress (CS). The time for each experiment was $2 \mathrm{~min}$. Measuring of each sample consisted of three separate stages. The first stage - the increase of the rotation speed from 0 to $1000 \mathrm{~min}^{-1}$. The second stage maintaining the rotation speed within $1000 \mathrm{~min}^{-1}$. The third stage - the decrease of the rotation speed from 1000 to 0 $\mathrm{min}^{-1}$. The measurements were carried out at different temperatures.

The rheological characteristics of the nanostructured binder in the system "modifier - cement" were studied on the same equipment keeping the same stages; but the rotation speed was from 0 to $1500 \mathrm{~min}^{-1}$.
The basic physico-mechanical properties of the modified binder (normal density, time for hardening and strength) were estimated in line with State Standard 30744-2001 «Cement. Testing methods with the use of polyfraction sand».

In order to determine the kinetic parameters for material drying, the authors used an electronic moisture detection device - an infrared moisture analyzer Sartorius MA35 at the temperature of $70{ }^{\circ} \mathrm{C}$ to intensify the process. As the final moisture value was taken such value, which did not change for 5 min at heating up.

The kinetics of material compositions strengthening, depending on the quantity of a modifier, was studies with the cubes sized $2 \times 2 \times 2 \mathrm{~cm}$, for which the value for the compression resistance was assigned as on 1, 3, 7, 14, 21 and 28 day.

The strength characteristics were studied for all compositions on the $28^{\text {th }}$ day according to the State Standard 10180-2012 "Concretes. Strength detection methods based on the controlling samples".

All the studies were conducted in BSTU in the Center of High Technologies, at the department Material Science and Material Technology.

\section{RESULTS AND DISCUSSIONS}

The first step in the research was to choose the parameter allowing to fully describe and give the characteristics to all compositions, taking into account their specificity. As such parameter was chosen the water-solid ratio of the system (W/S), expressed by the standard density of the paste.

The standard density of the cement paste is thought to be the consistency when a pestle of the Vicat apparatus (Tetmayer's pestle) being immersed in the ring, filled with the paste, does not reach 5-7 $\mathrm{mm}$ up to the plate on which the ring is mounted. This technological parameter shows the amount of water needed to create the optimal fluidity for the mixture. However, the water overabundance for the system of binders leads to the strength decrease and the detrimental of the exploitation material features. That is to say, the choice of the normal (standard) density of the paste as a parameter, which determines the amount of water in the system, is reasonable and approved by many factors. According to the data in table 6, each composition has its own $\mathrm{W} / \mathrm{S}$ ratio.

With increasing the modifier's proportion, the authors observe the water amount decrease in the system, needed to produce the normal density paste. It should be noted that for NB being in the natural state, the term "normal density" is not applicable. It causes that the binder possesses a high fluidity, regardless low W/S. The Vicat apparatus pestle reaches the bottom (composition 11). It is largely due to the specificity of the nanostructured binder.

In compositions 9 and 10, the cement entry leads to the liquid phase "deficiency", proving with the required fluidity that is associated with high absorption of the cement particles. The further increase of the cement substance in the 
system with the NB reduction (compositions 6-8) leads to the system stabilization and to the decrease of its water consumption aimed at providing the demanded fluidity. The latter is expressed with the decrease of the normal system density in a composite binder.

It is explained with the equal cement particles spreading over the suspension volume of the nanostructured binder. It provides with the formation of a solvate shell on the cement particles surface, needed to do the sorption processes with preserving the total system fluidity

TABLE VI. NORMAL DENSITY VALUES OF MODIFYING BINDER COMPOSITIONS

\begin{tabular}{|c|c|c|c|c|c|}
\hline \multirow{2}{*}{ No } & \multicolumn{2}{|c|}{ Composition, \% } & \multirow{2}{*}{ Normal density } & \multirow{2}{*}{ W/S } & \multirow{2}{*}{ W/C } \\
\cline { 2 - 3 } & NB & Cement & & 0.26 & 0.26 \\
\hline 1 & 0 & 100 & 0.26 & 0.25 & 0.28 \\
\hline 2 & 10 & 90 & 0.24 & 0.24 & 0.3 \\
\hline 3 & 20 & 80 & 0.22 & 0.24 & 0.34 \\
\hline 4 & 30 & 70 & 0.19 & 0.22 & 0.38 \\
\hline 5 & 40 & 50 & 0.17 & 0.28 & 0.56 \\
\hline 6 & 50 & 50 & 0.17 & 0.29 & 0.73 \\
\hline 7 & 60 & 40 & 0.16 & 0.31 & 0.99 \\
\hline 8 & 70 & 30 & 0.16 & 0.33 & 1.65 \\
\hline 9 & 80 & 20 & 0.16 & 0.35 & 3.48 \\
\hline 10 & 90 & 10 & 0.15 & 0.19 & - \\
\hline 11 & 100 & 0 & - & & \\
\hline
\end{tabular}

The very important factor in producing building composites is rheological characteristics of an applied binder and due to this fact the compositions viscosity was determined. Without paying attention to the ammount of modifier, all compositions possess typical thixotropic nature of the viscosity: initial viscosity, when the load is applied, equally decreases until the minimum value.

The compositions of the system "cement - modifier" were taken out when the paste density was normal. The compositions of the system "modifier - cement" were taken out at the W/S value of 0.45 . It is due to the fact that the cement paste has the same cone flow diameter as the "pure NB", that is to say the systems have the same degree of fluidity.

Considering the significant range of compositions viscosity values, it is not easy to depict graphically the rheological curves. That is why, the data are introduced in the table format (table 7). The shooting modes for the compositions rheological curves also differ due to the specificity of the predominant component.

The increase of modifier ammount in the composite binder promotes the reduction of the initial system viscosity. Small concentration of the added cement (compositions 9, 10) provides the 7-10 time increase of viscosity as compared with a highly diluted initial system, which is mostly linked with adsorption of the water on the cement particles.
TABLE VII. VISCOSITY VALUES OF BINDER COMPOSITIONS

\begin{tabular}{|c|c|c|c|c|c|c|c|c|c|c|c|}
\hline \multicolumn{12}{|c|}{ Quantity of modifier } \\
\hline \multirow{2}{*}{$\begin{array}{c}\text { Viscosity } \\
\text { value, } \\
\text { Pa } \times s\end{array}$} & \multirow{2}{*}{$\begin{array}{c}\begin{array}{c}\text { Pure } \\
\text { cement }\end{array} \\
0\end{array}$} & \multicolumn{4}{|c|}{$\begin{array}{c}\text { System } \\
\text { «cement-modifier» }\end{array}$} & \multicolumn{5}{|c|}{$\begin{array}{c}\text { System } \\
\text { «modifier -cement» }\end{array}$} & \multirow{2}{*}{\begin{tabular}{|c|} 
Pure \\
NB \\
100 \\
\end{tabular}} \\
\hline & & 10 & 20 & 30 & 40 & 50 & 60 & 70 & 80 & 90 & \\
\hline Initial & 14.5 & 12.5 & 12 & 10 & 4.1 & 322 & 320 & 280 & 279 & 150 & 15 \\
\hline Final & 3 & 1.9 & 1.85 & 1 & 0.3 & 20 & 22 & 22 & 10 & 20 & 5 \\
\hline
\end{tabular}

The introduction of the modifier into the system (compositions 2-5) reduces the initial viscosity of the binder. This is due to reducing a clinker presence in the system. When cement is blocked with water, the initial hydration processes in the spatial structure of the material begin. The introduction of $20 \%$ of NM (compositions 2-3) apparently does not change rheological characteristics of the binder qualitatively and quantitatively that occurs due to binding of the modifier active agent and Portlandite in cement that leads to coagulating structures formation in the material.

As the modifier substance increases in the system, along with the cement reduction, it is observed a component deficiency capable of making a spatial structure. This is marked with the viscosity reduction by 3.5 times, at the maximum NM substance. This is accomplished with several factors. The initial nanostructured binder is the system with a different-size disperse phase, spread over the disperse environment, which is separated with thin liquid interlayers. This provides the formation of a high-fluid system. The introduction of the cement into the suspension results in an increase of large-size particles requiring more disperse environment to ensure the desired fluidity because the total volume of a solid phase increases. This leads to some densification of the system and some reduction of a solvating shell on the solid phase surface. This is the reason for the increase of the system viscosity that leads to the reduction of the system fluidity. However, due to the thixotropic properties preservation of the suspension, that is very important for the building-purposed composites, the increase of the initial viscosity of studied systems is a positive feature because it allows to reduce or eliminate the shrinkage deformation at the early periods of hardening due to the fixation of primary structure.

To optimize the composites strength characteristics, it is very relevant to study the kinetics of the binders' strength.

For compositions 1-5, mainly because of a high cement concentration which hardening is occurring as the result of hydration, the kinetics of material strength depending on a modifier was studied. According to the data obtained, the kinetics of strength set in the compositions "cementmodifier" depending on the amount of a modifier differs insignificantly. The difference consists in strength indexes on a certain day. For the compositions with modifier concentration $20 \%$, the strength excess for one day as compared with the cement stone is $67 \%$, on the $28^{\text {th }}$ day $25 \%$. 


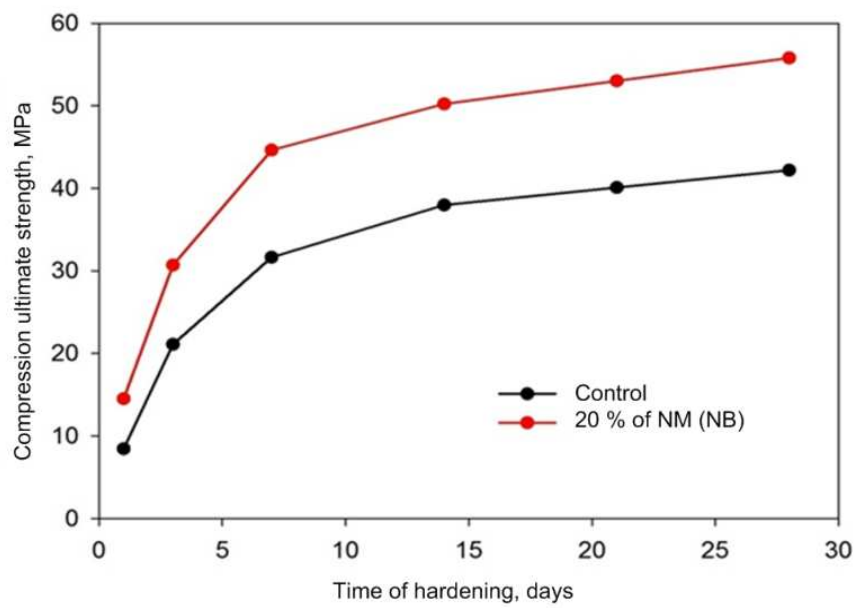

Fig. 3. Kinetics of resistance set for modified binder depending on a composition

Compositions 6-11, with prevailing of quartz component, possessing polymeric-polycondensate hardening type, are gaining strength due to removing spare moisture from the system, which makes drying problematic, both for a binder and for the composites themselves. The compositions of the system "modifier-cement" were trialed on the kinetics of drying. In this case, the Portland cement was used as the high-absorbing material capable of adhering spare water in the system. This can be attributed to a number of facts: cement is the hydroscopic material with high water absorption. In this case, the water absorbed with the cement particles will adhere chemically in the hydrohardening process. All this together results in the time reduction needed for the nanostructured binder drying and enables an increase of the matrix strength due to sealing and formation of a spatial carcass made from crystal newgrowth.

To compare them adequately, it is worth saying that the initial humidity of all compositions corresponded to the humidity of the initial (pure) nanostructured binder and amounted to $16 \%$ (figure 4 ).

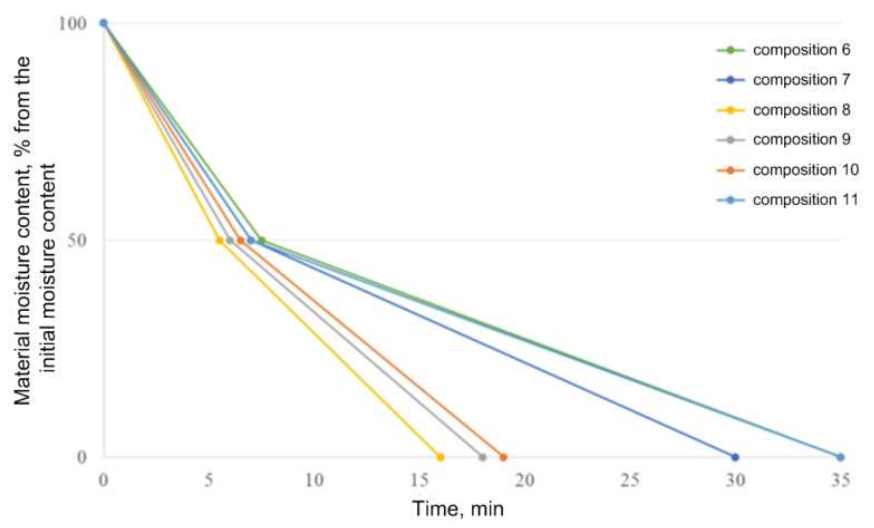

Fig. 4. Kinetic parameters for sample drying

Physico-mechanical properties of the compositions (their ultimate strength in compression and bending) were studied with the normal density of the cement paste (table 8).

The modifier introduction to the system also impacted positively the composite's strength characteristics: thus, in the system "cement-modifier", the introduction of a modifier in the amount of $20 \%$ from the dry components mass leads to the increase of the compression strength by $30 \%$ and bending strength by $12 \%$.

TABLE VIII. PHYSCO-MECHANICAL PROPERTIES OF STUDIED COMPOSITIONS

\begin{tabular}{|c|c|c|}
\hline No & $\begin{array}{c}\text { Ultimate bending } \\
\text { strength, MPa }\end{array}$ & $\begin{array}{c}\text { Ultimate compression } \\
\text { strength, } \mathbf{M P a}\end{array}$ \\
\hline 1 & 5.25 & 42.5 \\
\hline 2 & 5.9 & 45 \\
\hline 3 & 6.2 & 55.5 \\
\hline 4 & 5.8 & 42 \\
\hline 5 & 4.1 & 33 \\
\hline 6 & 4.5 & 28.22 \\
\hline 7 & 4.8 & 25.6 \\
\hline 8 & 4.22 & 28.5 \\
\hline 9 & 3.18 & 15.7 \\
\hline 10 & 1.21 & 7.8 \\
\hline 11 & 1.54 & 3.52 \\
\hline
\end{tabular}

In the compositions of the system "modifier-cement", positive influence of joint application of NB and cement is also observed: the ultimate compression strength comparing with "pure" NB for composition 8 with $30 \%$ of cement increases 9 times, the ultimate bending strength -4 times. Introduction of $\mathrm{NB}$ as a modifier enables intensification of the phase formation processes that leads to the formation of the rational set of crystal newgrowth, which affects primarily the growth in material strength properties.

\section{CONCLUSION}

The working assumption was evolved on the basis of the theoretical analysis focused on the approaches which are used for cement binders modification, likewise, for the nanostructured binder of the silicate composition gained within the technology by the wet staged grinding. The assumption is that NM can be used as a component in producing construction materials due to its modifying function. The authors attempted to illustrate in this study the efficacy of the use of the nanostructured binder of a silicate composition in order to produce the modified binder on the cement base. The use of the nanostructured modifier allows not only to increase the strength characteristics of the binder but also to optimize the rheotechnological characteristics. It is possible to point out compositions 3 and 8 with maximum strength characteristics as optimal. Their use as the main component in producing cellular concrete materials will enable one to increase the strength of the matrix carcass, the system stability and to improve the characteristics of finished products.

The positive factor of co-using the Portland cement and NB will be the decrease of the eco-pressure in the regions with a high production rate of the cement and civil building due to the lower emission to the atmosphere typically occurring during grinding and firing. NB entry into the production process will also lead to the energy cost reduction in material manufacturing which is subject to the specificity of the production process. 


\section{Acknowledgement}

Authors gratefully acknowledge the financial support of the Ministry of Education and Science of the Russian Federation, Federal Action Programme «Research and Development in Priority Fields of Science and Technology of the Russian Federation within 2014-2020», unique agreement identifier RFMEFI58317X0063.

\section{References}

[1] V.S. Lesovik, N.I. Alfimova, A.V. Savin, A.V. Ginzburg and N.N. Shapovalov, "Assessment of passivating properties of composite binder relative to reinforcing steel," World Applied Sciences Journal, vol. 24 (12), pp. 1691-1695, 2013.

[2] V.S. Lesovik, N.I. Alfimova and P.V. Trunov, "Reduction of energy consumption in manufacturing the fine ground cement," Research Journal of Applied Sciences, vol. 9 (11), pp. 745-748, 2014.

[3] R.V. Lesovik, S.V. Klyuev, A.V. Klyuev, S.A. Kazlitin, A.V. Netrebenko and A.V. Durachenko "Fiber-reinforced concretes made of technogenic raw materials and composite binders for industrial building floors", International Journal of Applied Engineering Research, vol. 9 (22), pp. 16711-16724, 2014.

[4] R.V. Lesovik, S.V. Klyuyev, A.V. Klyuyev, A.V. Netrebenko and N.V. Kalashnikov, "Fiber concrete on composite knitting and industrials and KMA for bent designs," World Applied Sciences Journal, vol. 30 (8), pp. 964-969, 2014

[5] V.S. Lesovik, L.A. Urkhanova, A.M. Gridchin and S.A. Lkhasaranov, "Composite binders on the basis of pearlite raw material of Transbaikalia,” Research Journal of Applied Sciences, vol. 9 (12), pp. 1016-1020, 2014

[6] N.I. Alfimova, V.V. Kalatozi, S.V. Karatsupa, Ya.Yu. Vishnevskaya and M.S. Sheychenko, "Mechanoactivation as the way to increase the efficiency of using raw materials of different genesis in construction materials science," The Bulletin of BSTU named after V.G. Shukhov, vol. 6, pp. 85-89, 2016.

[7] N.I. Alfimova, E.E. Shadskiy, R.V. Lesovik and M.S. Ageeva, "Organic-mineral modifier on the basis of volcanogenic-sedimentary rocks," International Journal of Applied Engineering Research, vol. 10 (24), pp. 45131-45136, 2015

[8] A.V. Cherevatova, "Principles of creating nanostructured binders based on HCBS," Refractories and industrial ceramics, vol. 51 (2), pp. 118-120, 2010.

[9] A. Ayzenshtadt, V. Lesovik, M. Frolova, A. Tutygin and V. Danilov, "Nanostructured wood mineral composite," Procedia Engineering, vol. 117, pp. 45-51, 2015.

[10] E.V. Korolev, "Nanotechnology in building materials science. Analysis of status and achievements. Paths of development," Construction materials, vol. 11, pp. 47-79, 2014.

[11] I. Flores, K. Sobolev, L.M. Torres-Martinez, E.L. Cuellar, P.L. Valdez and E. Zarazua, "Performance of cement systems with nano$\mathrm{SiO}_{2}$ particles produced by using the sol-gel method," Transportation research record, vol. 2141, pp. 10-14, 2010.

[12] K. Sobolev, Z.B. Lin, I. Flores-Vivian and R. Pradoto, "Nanoengineered cements with enhanced mechanical performance," Journal of the American Ceramic Society, vol. 99 (2), pp. 564-572, 2016.

[13] C. Gogtas, H.F. Lopez and K. Sobolev, "Effect of nano-YSZ and nano- $\mathrm{ZrO}_{2}$ additions on the strength and toughness behavior of selfflowing alumina castables," Ceramics International, vol. 42 (1), pp. 1847-1855, 2016.

[14] K. Sobolev "Modern developments related to nanotechnology and nanoengineering of concrete", Frontiers of structural and civil engineering, vol. 10 (2), pp. 131-141, 2016.

[15] A.V. Cherevatova and N.V. Pavlenko "Foam concrete based on nanostructured binder", The Bulletin of BSTU named after V.G. Shukhov, vol. 3, pp. 115-119, 2009.

[16] N.V. Pavlenko, V.V. Strokova, A.V. Cherevatova, D.D. Netsvet and E.V. Miroshnikov, "Cellular concretes based on nanostructured perlite binder," Applied Mechanics and Materials, vol. 496-500, pp. 2383-2386, 2014

[17] N.V. Pavlenko, V.V. Strokova, M.N. Kapusta and D.D. Netsvet "About application prospectivity of rocks with different geological and morphological features as basic raw component for free-cement binder production", Applied Mechanics and Materials, vol. 670-671, pp. 462-465, 2014

[18] N.V. Pavlenko "Analysis of the efficiency of foaming agents for the production of foam concrete of autoclave hardening on the basis of HCBS", The Bulletin of BSTU named after V.G. Shukhov, vol. 4, pp. 14-1, 20076.

[19] N.I. Altynnik and I.I. Podgorny "Development of cellular concrete on the basis of nanostructured binder", Proceedings of the International scientific-technological conference of young scientists of BSTU named V.G. Shukhov. Belgorod: BSTU, 2014, pp. 34-38. 